\title{
A educação de surdos no processo de ensino aprendizagem no campo das artes visuais ${ }^{1}$
}

Mirela Borges Martinho Freire

\footnotetext{
${ }^{1}$ Este artigo apresenta, de forma modificada, o projeto de pesquisa elaborado como requisito para a aprovação na disciplina Projeto Interdisciplinar ministrada pelo prof. Dr. Cayo Honorato no Curso de Graduação em Artes Visuais (Bacharelado/Licenciatura) pelo Departamento de Artes Visuais da Universidade de Brasília no primeiro semestre de 2017.
} 


\section{$\underline{\text { Introdução }}$}

Este projeto de pesquisa se propõe a considerar a linguagem gestual-visual ou visualespacial, como determinante para o processo de inserção da cultura surda no ensino regular, enfocando a utilização de imagens visuais como recursos pedagógicos. O presente projeto busca suscitar reflexões acerca da funcionalidade da identidade surda, discutindo a importância do bilinguismo na formação do cidadão e reconhecendo nas artes visuais um veículo de integração entre as línguas de sinais e as línguas orais.

Entende-se como ensino regular a formação acadêmica por meio do domínio da leitura, da escrita e do cálculo matemático. Porém, é nesse ponto que se nota a falha no sistema de educação. Visto que a inclusão consiste em desenvolver aulas e adequar o processo de aprendizagem de acordo com o ritmo dos alunos com deficiência, a integração consistiria em oferecer aos alunos com deficiências uma escola realmente inclusiva, na qual é a escola que se adapta às necessidades deles e não eles ao ensino regular, da escrita e da fala. O projeto pretende realizar uma pesquisa de caráter bibliográfico, baseando-se em teóricos a exemplo de: GOLDFELD (1997/2002), PERLIN (1998), QUADROS (2006), SACKS (1989), SILVA (2003) e VYGOTSKY (1989).

Diante destas considerações, o presente trabalho discorre sobre o contexto dos aspectos linguísticos das línguas de sinais a partir de um estudo sobre a importância da metodologia artística como mediadora de conhecimento entre a Língua Brasileira de Sinais (Libras) e a língua oral portuguesa. 


\section{Problematização do objeto}

A comunidade surda vista como uma minoria linguista e cultural é o grande questionamento que esse projeto busca estudar. A educação deve integrá-los na sociedade ou privilegiar a formação de uma identidade própria? Entender e conhecer os processos de inclusão de alunos surdos em uma comunidade ouvinte depende de uma formação bilíngue dos professores, logo, é primordial investir nessa formação do professor em contexto de sala, onde os sujeitos envolvidos são na maioria ouvintes.

\section{Revisão teórica}

De acordo com GOLDFELD (2002) e SACKS (1989), os primeiros educadores de surdos surgiram na Europa, no século XVI, criando diferentes metodologias de ensino. Já no Brasil, o primeiro órgão a desenvolver trabalhos com surdos e mudos surgiu em 1857. Foi do então Instituto dos Surdos-Mudos do Rio de Janeiro, hoje Instituto Nacional de Educação de Surdos (INES), que saíram os principais divulgadores da Língua Brasileira de Sinais (Libras).

O primeiro método utilizado para educar o sujeito surdo foi chamado de Oralismo, ou filosofia oralista. O oralismo percebe a surdez como uma deficiência que deve ser minimizada através da estimulação auditiva. (GOLDFELD, 1997, p. 30-31). Essa estimulação viria então a possibilitar o aprendizado da língua oral e a integração do surdo na comunidade ouvinte. Nesta filosofia são utilizados três elementos para o seu desenvolvimento, que são: o treinamento auditivo, a leitura labial e o desenvolvimento da fala, também o uso da prótese individual que amplifica os sons, com o objetivo de aproveitar os resíduos auditivos do aluno surdo, possibilitando aos mesmos a comunicação oral (SILVA, 2003). 
Os oralistas reprimiam quem não pudesse falar, atribuíam que os surdos deveriam aprender a língua falada, ainda que com essa estratégia os surdos não se desenvolvessem e não se integrassem socialmente, logo, a principal característica desse método é a ideia de que o surdo necessita aprender a língua oral de seu país, permitindo assim sua integração com a comunidade ouvinte. Porém, para a comunidade surda, essa metodologia de leitura de lábios e emissão de palavras, não obteve o sucesso esperado. A educação bilíngue surge então para romper com a concepção oralista e, nesse novo paradigma, não se discute somente a mudança metodológica, mas também ideológica, aceitando a língua de sinais como língua natural dos surdos e sua importância no processo educativo.

Com esse novo método de educação para surdos, a primeira língua ou a língua materna aprendida será aquela em contato direto com seu ambiente familiar, ou seja, para o sujeito surdo a primeira língua a ser aprendida será a Língua de sinais, em seguida aprimorada com a sua convivência na comunidade surda.

Assim, a educação bilíngue é uma filosofia de ensino que recomenda o acesso a duas línguas no contexto escolar, sendo a Língua de Sinais considerada como língua natural e por meio dela será realizado o ensino da língua escrita. Essa filosofia resgata o direito da pessoa surda de ser ensinada na Língua de Sinais, respeitando-se seus aspectos sociais e culturais (BRASIL, 2004). 


\section{Identidade e cultura surda}

Em relação à construção da identidade surda, o espaço da educação básica também mostra-se pouco propício, uma vez que a criança surda estará, em geral, sozinha (em sua condição de não ouvinte), sem contato com outros surdos, coetâneos ou adultos, o que favoreceria a construção de uma imagem positiva em relação a sua surdez (PERLIN, 1998). A identidade cultural surda é formada através do pertencimento a uma cultura, por isso, a cultura surda é o local onde o surdo constrói sua subjetividade de forma a assegurar a sua sobrevivência e a ter seu status dentro das múltiplas culturas. (QUADROS, 2006) A integração das crianças surdas com as ouvintes faz com que haja uma construção social empática, com que se perceba quem está ao seu redor e o que elas têm a acrescentar nesse processo formador. Ainda segundo QUADROS (2001: 59), "a cultura surda tem características peculiares, específicas diante das demais culturas". QUADROS (2001: 60) ainda acrescenta que "a cultura surda é multifacetada, é própria do surdo, se apresenta de forma visual onde o pensamento e a linguagem são de ordem visual e por isso é tão difícil de ser compreendida pela cultura ouvinte”.

Tendo-se como pressuposto que a identidade é um fenômeno dinâmico e social, ou seja, ocorre por intermédio das relações Inter psicológicas, abrangendo, então, experiências sociais e modos de comunicação, o pertencimento a um grupo social com uma forma característica de linguagem é de extrema importância para a constituição do sujeito. Uma vez que o termo linguagem tem um sentido bastante amplo, a linguagem é tudo que envolve significação, que tem um valor semiótico e não se restringe apenas a uma forma de comunicação. É pela linguagem que se constitui o pensamento verbal do indivíduo. Assim, a linguagem está sempre presente no sujeito, mesmo no momento em que este não se comunica com outras pessoas. A linguagem constitui o sujeito, a forma como este recorta e percebe o mundo e a si próprio (GOLDFELD, 2002; GÓES, 1999; VYGOTSKI, 1996). 
QUADROS (2006: 57), afirma que "[...] a identidade surda se constrói dentro de uma cultura visual, essa diferença precisa ser entendida não como uma construção isolada, mas como construção multicultural". Dessa forma, entende-se que a identidade dos surdos necessita de estratégias de implementação de contextos educacionais inclusivos, entre elas, a utilização de imagens visuais como proposta de inclusão da identidade surda no ensino regular.

\section{Bilinguismo na educação básica}

A educação bilíngue de surdos no Brasil está amparada pela Lei e é recomendada pelo Ministério Nacional da Educação (MEC), como sendo uma proposta válida e eficaz para o ensino das duas Línguas reconhecidas pelo país: a Língua Portuguesa e a Libras, necessárias para a inclusão social efetiva destes sujeitos. O Decreto $n^{\circ} 5.626$ de 22/12/2005, que regulamenta a Lei $n^{\circ}$ 10.436/2002, em seu capítulo VI, artigo 22, determina que se organize, para a inclusão escolar:

I - escolas e classes de educação bilíngue, abertas a alunos surdos e ouvintes, com professores bilíngues, na educação infantil e nos anos iniciais do ensino fundamental; II - escolas bilíngues ou escolas comuns da rede regular de ensino, abertas a alunos surdos e ouvintes, para os anos finais do ensino fundamental, ensino médio ou educação profissional, com docentes de diferentes áreas do conhecimento, cientes da singularidade linguística dos alunos surdos, bem como a presença de tradutores e intérpretes de Libras Língua Portuguesa. (NOVAES, 2010, p. 73).

Ainda no artigo 22, parágrafo $1^{\circ}$, este Decreto descreve como escola ou classe de ensino bilíngue "aquelas em que a Libras e a modalidade escrita da Língua Portuguesa sejam língua de instrução utilizada no desenvolvimento de todo o processo educativo”. O reconhecimento pela Lei brasileira $n^{\circ}$ 10.436/2002 da Libras como língua oficial abriu o caminho para a educação bilíngue para os surdos e a aceitação da existência de uma "cultura surda". 
Vygotsky (1989) explicita que se uma criança estiver inserida em uma comunidade e utilizar uma língua em suas interações com os membros da mesma, valer-se-á desta língua tanto para comunicar-se como para o seu desenvolvimento cognitivo, a partir da internalização desta língua.

Blanc (apud MEGALE, 2005: 11) afirma que a educação bilíngue é determinada por fatores históricos, sociais, ideológicos, psicológicos e variadas relações de poder. E todos estes fatores devem ser levados em consideração quando se decide pelo modelo ou programa em educação bilíngue.

Assim, a Língua Brasileira de Sinais é um marco referencial essencial nos processos de ensino-aprendizagem da comunidade surda. É através da utilização dessa linguagem, visual-espacial, que ocorre a inserção dos surdos nas linguagens orais, acrescentando uma formação bilíngue para o sistema educacional e integrador.

\section{A linguagem visual como mediadora de conhecimento}

Para Arnhein (1957) as principais estruturas que compõem a percepção visual estão centradas em equilíbrio, figura, forma, espaço, luz, cor, movimento, dinâmica e expressão. Por sua vez, Dondis (1991) nos apresenta elementos que fundamentam os aspectos compositivos da sintaxe visual, tais como: ponto, linha, forma, cor e luz.

A linguagem visual e seus elementos compõem uma estratégia de ensino para a educação da Língua de sinais, pois é através dessa linguagem que as crianças aumentam sua capacidade de expressão e percepção do mundo. Logo, é importante utilizar a Arte visual como recurso que auxilia na formação da criança. A comunicação faz com que haja interpretação social maior e, além do processo da construção do conhecimento, faz com que se pense na realidade de quem permeia o ambiente. 
Em contrapartida, Reily (2004: 29) destaca que no trabalho pedagógico com imagens, a significação "não está na percepção sensorial, mas, sim, no movimento de síntese e de interpretação” e, nesse sentido, torna-se necessário “avançar para sintetizar o sentido geral que o artista pretende comunicar".

É importante utilizar a Arte visual como recurso que auxilia na formação da criança surda, visto que a percepção visual é intrínseca no processo de ensino aprendizagem de um aluno surdo, a apropriação da linguagem visual-espacial torna-se então indispensável nesse processo. É por meio da arte, os surdos dialogam não só com os seus familiares e pessoas próximas, mas também com a sociedade na qual estão inseridos. Isso toma proporções ainda maiores com a internet, que ultrapassa qualquer fronteira geográfica.

Há, dessa forma, uma democratização da informação, através da inserção do discurso de grupos que historicamente são excluídos dos meios tradicionais de comunicação. Por isso, é de extrema importância a criação e desenvolvimento de iniciativas que se utilizem da arte para garantir a inclusão de pessoas com deficiência. Nesse contexto, as artes, sobretudo as visuais, surgem como um canal capaz de gerar mudanças. A imagem, concebida pela fotografia, por vídeos ou pinturas, por exemplo, pode ser utilizada como uma poderosa ferramenta pedagógica e comunicacional. Ela comunica a partir do momento em que é pensada, produzida, até quando é contemplada por outras pessoas, ocasionando reações, reflexões e sentimentos distintos. No caso de pessoas surdas, os estímulos visuais são ainda mais importantes, pois são sua principal forma de comunicação com o mundo, já que seus olhos fazem também o papel dos ouvidos. Além disso, a participação em atividades culturais estimula a criatividade e o pensamento crítico, contribuindo com o desenvolvimento de cada um. Como afirma Heloisa Bezerra, formada em jornalismo pela Universidade de Pernambuco. 
Justificativa

O desenvolvimento desse trabalho se deu a partir do meu interesse sobre a surdez e a escolha do objeto de pesquisa aconteceu através da convivência com a comunidade surda no meio da arte-educação.

A inclusão da linguagem de sinais no processo de ensino-aprendizagem entre os alunos ouvintes e surdos com a comunidade escolar é difícil, visto que a comunidade surda é uma minoria dentro da cultura hegemônica e isso se repete na comunidade escolar. A compreensão de que a surdez é considerada maldição, loucura ou patologia gera condições de exclusão ou discriminação, coloca os surdos às margens do mundo social, político, econômico, educacional e cultural.

A discussão da língua de sinais dentro do ensino regular proporciona o desenvolvimento dos ouvintes com a linguagem visual espacial, trabalhando coordenação motora, a sensibilidade em se comunicar para além da perspectiva da língua falada, fazendo-se habitual e essencial para os alunos em sua formação, e na interação para com os alunos surdos. Fazer com que os surdos adentrem no universo dos ouvintes faz com que a integração social e cultural entre a língua de sinais e a língua oral, seja facilitadora de um aprendizado na educação de ensino regular. Dessa forma integra-se a comunidade surda na cultura que se diz hegemônica. Porém existe uma enorme distância entre a teoria e o que realmente tem acontecido nas escolas, como diz Ângela da Silva:

[...] há um imenso abismo entre o mundo acadêmico e o cotidiano escolar. Este cotidiano nos revela, ainda hoje, uma grande lacuna entre o que é realmente proposto em lei, o desenvolvimento do conhecimento produzido nas universidades e a realidade de nossas escolas no que se refere à educação de surdos. Diferentes práticas pedagógicas têm sido desenvolvidas e aplicadas quanto à educação de surdos. No entanto, nota-se que um grande número de surdos, ao concluir sua escolarização básica, não é capaz de ler e escrever fluentemente ou de ter domínio sobre os conteúdos pertinentes a este nível de escolarização. Pode-se, aqui, inferir que esta lacuna esteja diretamente ligada a uma série de fatores que vêm acompanhando o processo educacional do surdo por gerações. (SILVA, 2005: 43) 
A pesquisa busca então agregar, por meio de intervenções urbanas, a comunidade surda nas atividades culturais e artísticas. Nesse contexto, os surdos encontram um campo propício para o desenvolvimento da sua capacidade criativa, como artista e cidadão, permitindo sua inclusão socioeconômica no país.

A plataforma tecnológica, mais especificamente as redes sociais, também surgem como veículo de integração da comunidade surda com a comunidade ouvinte. É através de aplicativos, que compartilham imagens e vídeos, que a cultura surda têm aumentado a troca de informações, assim suas percepções visuais estão ganhando uma nova ferramenta de comunicação. Dessa forma entende-se que a formação da identidade dos surdos está atrelada a estratégias de implementação de contextos educacionais inclusivos, apropriando-se das artes visuais como mediadora do conhecimento.

\section{Exercício analítico}

Utilizar a linguagem visual para a inserção dos surdos e integração com alunos ouvintes na linguagem de sinais.

\section{Objetivos}

Através da arte visual, fazer com que ocorra a integração da identidade surda com a ouvinte, tornando possível e acessível a comunicação entre duas comunidades na educação do ensino básico.

- Demonstrar a importância do sujeito surdo adquirir sua língua materna (Língua de sinais);

- Entender o processo de formação do professor com a educação básica e a Libras

- Analisar como a linguagem visual-espacial proporcione a integração entre os alunos surdos e ouvintes na comunidade escolar. 


\section{Metodologia}

A Intervenção Urbana é o termo utilizado para designar os movimentos artísticos relacionados às intervenções visuais realizadas em espaços públicos e são manifestações organizadas por grupos de artistas com o propósito de transmitir mensagens. Elas são um tipo de arte que tem o objetivo de questionar e transformar a vida cotidiana e lançam no espaço público questões que provocam discussões em toda a população. De uma maneira ou de outra, ela faz com que as pessoas parem sua rotina por alguns minutos, seja para questionar, criticar ou simplesmente contemplar a arte.

A pesquisa será feita a partir de um levantamento bibliográfico, com o objetivo de coletar informações e conhecimentos prévios, para sua estruturação. De acordo com AlvesMazzotti e Gewandsznajder (2002), toda pesquisa supõe dois tipos de revisão da literatura: aquela que o pesquisador necessita para seu consumo, isto é, para ter clareza sobre as principais questões teórico-metodológicas pertinentes ao tema escolhido e aquela que vai, efetivamente, contribuir com o embasamento teórico das análises realizadas ao final do estudo.

O projeto visa um mapeamento nas escolas onde alunos surdos estudam, para levantamento de dados e posteriormente para a elaboração do material necessário. Essas intervenções serão feitas através do método de colar cartazes pelos espaços públicos da cidade, também conhecida como "lambe-lambe".

Com a premissa de estimular a linguagem visual desenvolvida pelo sujeito surdo desde seu nascimento, o projeto visa elaborar o alfabeto manual dos surdos (formato das letras feito pelas mãos) em papel A3, contendo cada letra em uma página. Com isso espalharemos pela cidade frases feitas pela comunidade surda dialogando e provocando na comunidade ouvinte o seguinte questionamento: "Por que você não fala comigo?" 
Fazer com que a comunidade surda dialogue através das intervenções artísticas urbanas com a comunidade ouvinte é um dos propósitos que essa pesquisa propõe. Fazendo a conexão com a linguagem dos surdos e mostrando a acessibilidade da leitura em Libras, surge assim uma possibilidade de comunicação entre as comunidades.

3. Carta de intenções

Serão realizadas oficinas explicativas para a produção dos materiais, desde o uso dos papéis até a produção de cola para grudar os cartazes. A intervenção visa introduzir os materiais que serão trabalhados durante a colagem na rua, como a produção de cola caseira, os tipos de canetas e as temáticas que circundam o assunto. Dessa maneira pretende-se atrair os alunos, surdos e ouvintes, no contato com a arte visual.

Haverá discussão da importância da comunicação e da linguagem, fazendo a escolha do conteúdo poético para a interação no espaço de intervenção, o que conta tanto no ambiente externo, como as pessoas que ali frequentam. Seguindo na produção do material para a colagem, faz-se o recorte do alfabeto em Libras. Com o intuito de construir uma poesia que permeia entre incluir os surdos nas atividades artísticas, por vez que eles já têm o domínio da linguagem visual espacial, havendo uma identificação dessa arte com a linguagem dos surdos.

Então os lugares serão definidos em conjunto com os alunos e posteriormente a saída para realizar a colagem. A importância deles estarem com contato com todas as etapas dessa intervenção é construir o diálogo entre a linguagem oral e visual. 


\section{Referências}

- Ministério da Educação e Cultura. Ensino de língua portuguesa para surdos: caminhos para a prática pedagógica. Brasília: MEC, SEESP, 2v. 2004. Disponível em:. Acesso em: 01 jul. 2017.

ALVES-MAZZOTTI, Judith.; GENANDESZNAJDER, Fernando. O método das ciências naturais e sociais: pesquisa quantitativa e qualitativa. Rio de Janeiro: Graphica Editorial, 2002.

ARNHEIN, R. Arte e percepção visual: uma psicologia da visão criadora. São Paulo: Edusp, Pioneira, 1989.

BRASIL - Lei Federal 10.436 - Dispõe sobre a Língua Brasileira de Sinais - Libras. Presidência da República, 2002.

BRASIL, Decreto $N^{\circ} 5.626$ - regulamenta a Lei no 10.436, de 24 de abril de 2002, que dispõe sobre a Língua Brasileira de Sinais - Libras, e o art. 18 da Lei no 10.098, de 19 de dezembro de 2000, Presidência da República, 2005.

BRASIL. Lei 10.436, de 24 de abril de 2002. Dispõe sobre a Língua Brasileira de Sinais (LIBRAS) e dá outras providências. Disponível em: MENEZES, Ebenezer Takuno de. SANTOS, Thais Helena dos. "LIBRAS (Língua Brasileira de Sinais)" (Verbete).

DONDIS, D. A Sintaxe da linguagem visual. São Paulo: Martins Fontes, 1991.

GÓES, Maria Cecília Rafael. Linguagem, Surdez e Educação. 2. ed. São Paulo: Autores Associados, 1999.

GOLDFELD, M. A criança surda: linguagem e cognição numa perspectiva sócio interacionista. São Paulo: Plexus, 1997/2002.

LACERDA, C.B.F. A inserção da criança surda em classe de crianças ouvintes: focalizando a organização do trabalho pedagógico. In: REUNIÃO ANUAL DA ANPED, 23, 2000, Caxambú. Anais. Caxambú: ANPED, 2000. Disponível em: Acesso em: 2000.

LORENZINI, N.M.P. Aquisição de um conceito científico por alunos surdos de classes regulares do Ensino Fundamental. 2004. Dissertação (mestrado em Educação), Universidade Federal de Santa Catarina, Florianópolis, 2004.

MEGALE, Antonieta Heyden. Bilingüismo e educação bilíngüe - discutindo conceitos. Revista Virtual de Estudos da Linguagem - ReVEL. V. 3, n. 5, agosto de 2005. ISSN 1678-8931 [www.revel.inf.br].

MENEZES, Ebenezer Takuno de. SANTOS, Thais Helena dos. "LIBRAS (Língua Brasileira de Sinais)". Dicionário Interativo da Bducação Brasileira.

Educa Brasil. São Paulo: Midiamix Editora, 2006.

NOVAES, E. C. Surdos: educação, direito e cidadania. Rio de Janeiro: Wak, 2010.

PERLIN, G. Identidades Surdas. In: SKLIAR, C. (Org.) A Surdez: um olhar sobre as diferenças. Porto Alegre: Editora Mediação, 1998.

QUADROS, R. M. de. Educação de surdos: a aquisição da linguagem. Porto Alegre: Artes Médicas. 1997.

QUADROS, Ronice Muller. Educação de surdos. Porto Alegre: Artes Médicas, 1997. 
REILY, L. Recursos pedagógicos: a imagem visual em duas dimensões e a imagem em movimento. In: Escola Inclusiva: linguagem e mediação. Campinas: Papirus, 2004.

SACKS, O. Vendo Vozes: uma Jornada pelo Mundo dos Surdos. Rio de Janeiro: Companhia das Letras, 1990.

SILVA, A. c. da. A representação social da surdez: entre o mundo acadêmico e o cotidiano escolar. In: Surdez e bilinguismo. Eulália Fernandes (org.). Porto Alegre: Editora Mediação, 2005.

SILVA, V. et al. Educação de surdos: Uma Releitura da Primeira Escola Pública para Surdos em Paris e do Congresso de Milão em 1880. In: QUADROS, R. M. (Org). Estudos surdos I. Petrópolis, RJ: Arara Azul, 2006. p.324.

SKLIAR, Carlos, Educação \& exclusão: abordagens sócio antropológicas em educação especial. Porto Alegre: Editora Mediação, 1997.

STROBEL, K. As imagens do outro sobre a cultura surda. Florianópolis: Editora da UFSC, 2008.

VIGOTSKI, L.S. Teoria e Método em Psicologia. São Paulo: Martins Fontes, 1996.

VIGOTSKI, L.S. A construção do pensamento e da linguagem. São Paulo: Martins Fontes, 2001. 